\title{
PROPERTIES OF AN ANTICOAGULANT FOUND IN THE BLOOD OF A HEMOPHILIAC
}

\author{
BY F. L. MUNRO \\ (From the Charlotte Drake Cardeza Foundation, Department of Medicine, Jefferson Medical \\ College and Hospital, Philadelphia)
}

(Received for publication December 28, 1945)

Munro and Jones (1) have reported on a case of hemophilia who, apparently as the result of frequent transfusions, had developed a phase in which further transfusions failed to cause either a reduction in his coagulation time or clinical improvement. At that time it was demonstrated that the blood of this patient contained an anticoagulant. It was suggested that the numerous transfusions were responsible for the development of this anticoagulant. Further study has tended to confirm this interpretation.

There have been two previous reports of the presence of an abnormal circulating anticoagulant. Lawrence and Johnson (2) have presented a study on a hemophiliac similar to this case. The diagnosis of hemophilia was established by both the clinical findings and the family history. The patient, however, was refractory to transfusions and had a circulating anticoagulant with properties closely allied to those found in this case. They reported that he had received many transfusions but did not state whether the anticoagulant was known to be present during a period when transfusions were not given. Lozner, Jolliffe and Taylor (3) have described a 61-year-old Negro who had a circulating anticoagulant which they were unable to identify. In this case the diagnosis of hemophilia was excluded on the basis of both the past history and the family history.

Tocantins (4) has described a normally occur-

TABLE I

The anticoagulant action of the patient's plasma on normal plasma

\begin{tabular}{c|c|c|c|c}
\hline \hline $\begin{array}{c}\text { Patient's } \\
\text { plasma }\end{array}$ & $\begin{array}{c}\text { Normal } \\
\text { plasma }\end{array}$ & $\begin{array}{c}\text { Sodium } \\
\text { chloride } \\
\text { 0.15 M }\end{array}$ & $\begin{array}{c}\text { Calcium } \\
\text { chloride } \\
\text { 0.025 M }\end{array}$ & $\begin{array}{c}\text { Coagulation } \\
\text { time }\end{array}$ \\
\hline$m l$. & $m l$. & $m l$. & ml. & min. \\
0.00 & 0.40 & 0.40 & 0.40 & 3 \\
0.05 & 0.40 & 0.30 & 0.45 & 4 \\
0.10 & 0.40 & 0.20 & 0.50 & 12 \\
0.15 & 0.40 & 0.10 & 0.55 & 43 \\
0.20 & 0.40 & 0.00 & 0.60 & 50 \\
0.20 & 0.00 & 0.40 & 0.20 & 150 \\
\hline
\end{tabular}

ring anticoagulant which he names antithromboplastin, or anticephalin. He has found this substance to be abnormally high in hemophilia and considers it to be the cause of the prolonged coagulation time in this disease. As will be shown, the anticoagulant discussed here is not anticephalin.

It is the purpose of this paper to describe some of the properties of this anticoagulant. Further clinical observations on this patient will be discussed in a later paper.

\section{EXPERIMENTAL PROCEDURE}

Studies with this anticoagulant in unfractionated plasma showed that it could most easily be studied by the following technique: blood was collected from the patient by venepuncture and mixed with $1 / 6$ of its volume of $0.1 \mathrm{M}$ sodium oxalate. It was then centrifuged for 1 hour at $2000 \mathrm{rpm}$ and the plasma removed. Various quantities of the plasma were then added to $0.4 \mathrm{ml}$. of normal plasma prepared in the same manner. The mixture was recalcified by the addition of an equal volume of $0.025 \mathrm{M}$ calcium chloride, the total volume being adjusted to $1.2 \mathrm{ml}$. by the addition of the requisite amount of $0.15 \mathrm{M}$ sodium chloride. A typical experiment showing the effect of increasing amounts of this plasma is given in Table $I$. Experience showed that $0.2 \mathrm{ml}$. of this plasma with $0.4 \mathrm{ml}$. of normal plasma generally gave a satisfactory coagulation time. Accordingly, in studying the various properties of the anticoagulant the coagulation time was determined in a mixture containing $0.2 \mathrm{ml}$. of this plasma, 0.4 $\mathrm{ml}$. of normal plasma, and $0.6 \mathrm{ml}$. of $0.025 \mathrm{M}$ calcium chloride. Since this procedure was followed in a majority of the experiments the details will not be repeated for each one. Variations from it will be described in any particular case.

\section{RESULTS}

The studies made on this anticoagulant may be divided into three main groups. These are: (1) the properties of the anticoagulant in unfractionated plasma, (2) the relation of the anticoagulant to the various factors involved in the coagulation mechanism, and ( 3 ) the fractionation of the plasma with the object of determining the nature of the active material. 


\section{(1) Properties of the anticoagulant in unfraction- ated plasma}

\section{The effect of incubating the patient's plasma with normal plasma}

The patient's plasma was mixed with twice its volume of normal plasma and incubated at $37^{\circ} \mathrm{C}$. At intervals, as shown in Table II, $0.6 \mathrm{ml}$. of the mixture was removed, $0.6 \mathrm{ml}$. of $0.025 \mathrm{M}$ calcium chloride added, and the clotting time determined. At the same intervals a fresh mixture containing $0.2 \mathrm{ml}$. of the patient's plasma and 0.4 ml. of normal plasma was prepared and recalcified in the same way. The clotting time of the incubated mixture and the newly prepared mixtures were parallel over a period of 24 hours. It appears, therefore, that the activity of this anticoagulant is not decreased by incubation with normal plasma.

\section{The effect of storage and temperature}

Plasma prepared in the usual way was tested for its anticoagulant activity on the day of collection and stored in the refrigerator. At intervals the plasma was tested for its anticoagulant activity against fresh normal plasma. As shown in Table III, no decrease in anticoagulant occurred during a period of 10 days.

Quantities of $5 \mathrm{ml}$. of the plasma were heated for $\mathbf{5}$ or $\mathbf{1 0}$ minutes at various temperatures. The samples were then centrifuged to remove any precipitate which had formed and tested for anticoagulant activity. There was no decrease in the activity in any of the samples (Table IV).

TABLE II

The effect of incubating the patient's plasma with normal plasma

\begin{tabular}{c|c|c}
\hline \hline \multirow{2}{*}{ Incubation time } & \multicolumn{2}{|c}{ Coagulation time* } \\
\cline { 2 - 3 } & Incubated & Not incubated \\
\hline hours & mir. & min. \\
0 & 22 & 20 \\
1 & 18 & 18 \\
3 & 23 & 19 \\
4 & 27 & 27 \\
5 & 22 & 25 \\
24 & & \\
\hline
\end{tabular}

* Each test was made using $0.2 \mathrm{ml}$. of the plasma, 0.4 $\mathrm{ml}$. of normal plasma, and $0.6 \mathrm{ml}$. of $0.025 \mathrm{M}$ calcium, chloride.

Coagulation time of normal plasma $6 \mathrm{~min}$.
TABLE III

The effect of storage

$\begin{array}{cc}\text { Storage time } & \text { Coagulation time* } \\ \text { days } & \text { min. } \\ 0 & 42 \\ 1 & 40 \\ 2 & 40 \\ 4 & 41 \\ 10 & 46\end{array}$

* Each test was made using $0.2 \mathrm{ml}$. of the plasma, 0.4 $\mathrm{ml}$. of normal plasma and $0.6 \mathrm{ml}$. of $0.025 \mathrm{M}$ calcium chloride.

Coagulation time of normal plasma $6 \mathrm{~min}$.

TABLE IV

The effect of temperature

\begin{tabular}{|c|c|c|}
\hline Temperature & Time & Coagulation time* \\
\hline $\begin{array}{l}{ }^{\circ} \mathrm{C} . \\
45 \\
55 \\
65 \\
65\end{array}$ & $\begin{array}{r}\min . \\
5 \\
5 \\
5 \\
10\end{array}$ & $\begin{array}{c}\min . \\
22 \\
24 \\
24 \\
27 \\
24\end{array}$ \\
\hline
\end{tabular}

* Each test was made using $0.2 \mathrm{ml}$. of the plasma, 0.4 $\mathrm{ml}$. of normal plasma, and $0.6 \mathrm{ml}$. of $0.025 \mathrm{M}$ calcium chloride.

Coagulation time of normal plasma $6 \mathrm{~min}$.

These data indicate that the anticoagulant is very stable to both storage and heat. The only normally occurring anticoagulant which is not inactivated by the amount of heat applied to this plasma is antithrombin (5). As will be shown later, it has not been possible to demonstrate an increase in antithrombin in this plasma. Tocantins (4) has studied the effect of heating on anticephalin. He finds that anticephalin is not stable at temperatures above $50^{\circ} \mathrm{C}$. It appears, therefore, that this anticoagulant is not anticephalin.

\section{The relative activity of oxalated, citrated or un- modified whole blood and plasma}

Blood from the patient was handled as follows: one part was mixed with $1 / 9$ of its volume of 0.1 M sodium oxalate, a second with $1 / 9$ of its volume of 3 per cent sodium citrate, and the remainder left without anticoagulant. Studies were made of the anticoagulant activity of the three blood samples and the three corresponding plasma samples. This was done by adding the necessary amount of calcium chloride and then adding $1.0 \mathrm{ml}$. of freshly drawn unmodified normal blood. Tests on all six materials were performed at the same time, approximately 90 minutes after collecting the blood. 
TABLE V

The relative activity of oxalated, citrated or unmodified whole blood and plasma

\begin{tabular}{l|c|c}
\hline \hline \multirow{2}{*}{ Anticoagulant } & \multicolumn{2}{|c}{ Coagulation time of* } \\
\cline { 2 - 3 } & Whole blood & Plasma \\
\hline \multirow{3}{*}{ None } & $\min$. & $\min$. \\
Sodium Oxalate & 20 & 45 \\
Sodium Citrate & 20 & 35 \\
& 20 & 36 \\
\hline
\end{tabular}

* $1 \mathrm{ml}$. of blood, or $0.55 \mathrm{ml}$. of plasma were mixed with $1 \mathrm{ml}$. of normal blood.

Coagulation time of normal blood $6 \mathrm{~min}$.

All the preparations of both blood and plasma had a definite anticoagulant effect (Table V). The plasma samples containing oxalate or citrate when recalcified showed less activity than the unmodified sample. This decrease in activity is probably due to lysis of the platelets which occurs during the process of decalcification and subsequent recalcification. This process, resulting in an increased supply of thromboplastin, would tend to accelerate the clotting mechanism. In the whole blood samples there was no difference between the samples containing oxalate or citrate and the unmodified sample. In this case the number of platelets was not decreased by centrifuging and the continued disintegration during the period of standing would result in the decreased clotting time observed with the whole blood as compared to the plasma.

\section{The effect of hydrogen ion concentration}

Quantities of $3 \mathrm{ml}$. of the plasma were adjusted to various hydrogen ion concentrations from $\mathrm{pH}$ 5.0 to 11.0 and left at these concentrations for 3 hours. They were then returned to $\mathrm{pH} 7.6$ to 7.8 and tested for anticoagulant activity. Precipitation occurred in the samples brought to $\mathrm{pH} 6.0$ and below and $\mathrm{pH} 10.0$ and above. On neutralizing, these precipitates redissolved in the $\mathrm{pH} 6.0$ and 10.0 samples, but the others remained turbid. The anticoagulant activity decreased markedly in the samples brought to $\mathrm{pH} 5.0$ and 5.5 and slightly in the sample brought to $\mathrm{pH} 6.0$. There was no alteration in activity in any sample from $\mathrm{pH} 6.5$ to 11.0 inclusive (Table VI).

(2) Relation of the anticoagulant to various components of the coagulation mechanism

Quick (6) in his discussion of anticoagulants lists five possible types, namely decalcifying agents, antiprothrombins, antithromboplastins, fibrinogen antagonists, and antithrombins. Studies have been made of this anticoagulant with the object of détermining which component of the coagulation mechanism it affected. Since it has so far not been possible to demonstrate that this anticoagulant falls into any of the above classes, the experiments made to determine its type will be described only briefly.

The concentration of calcium chloride used in recalcifying this plasma alone, and mixtures of this plasma with normal plasma was varied over a range of $0.015 \mathrm{M}$ to $0.050 \mathrm{M}$. The minimum coagulation time in each case was obtained at the same concentration as that for normal plasma, namely $0.025 \mathrm{M}$ calcium chloride.

The prothrombin time of the plasma has been determined by the one-stage method on various occasions. It has been found to be the same as that of normal plasma, which would not be the case if an antiprothrombin were present.

While plasma from this patient has been shown to contain antithromboplastin by the special methods described by Tocantins, the procedures by which it has been handled in this laboratory are such that antithromboplastin would become inactivated. Blood has been collected without special precautions and treated in numerous ways which are reported to inactivate antithromboplastin without any. resulting inactivation of this anticoagulant. For these reasons as well as the differences in stability and chemical behavior described elsewhere in this paper, the data indicate that if this anticoagulant is an antithromboplastin, it is not the same antithromboplastin that has been described by Tocantins.

While the coagulation of this plasma, either

TABLE VI

$\begin{array}{cc}\begin{array}{c}\text { The effect of hydrogen ion concentration } \\ \text { pH }\end{array} & \begin{array}{c}\text { Coagulation time* } \\ \text { min. }\end{array} \\ & 29 \\ 5.0 & 34 \\ 5.5 & 39 \\ 6.0 & 45 \\ 6.5 & 46 \\ 8.0 & 50 \\ 9.0 & 45 \\ 9.5 & 53 \\ 10.0 & 45\end{array}$

* Each test was made using $0.2 \mathrm{ml}$. of the plasma, 0.4 ml. normal plasma and $0.6 \mathrm{ml} .0 .025 \mathrm{M}$ calcium chloride. Coagulation time of normal plasma $3 \mathrm{~min}$. 
alone or mixed with normal plasma, was delayed, the clot which formed was normal. For this reason it was not considered probable that the anticoagulant was a fibrinogen antagonist.

Determination of the antithrombin activity of this plasma by the method described by Wilson (7) showed that there was no increase in antithrombin compared to that of normal plasma. Addition of protamine ${ }^{1}$ in quantities of 0.001 to $0.1 \mathrm{mgm}$. per ml. of plasma or whole blood caused no reduction of the clotting time. Since protamine is known to be a precipitant of heparin it may be assumed that the anticoagulant is not heparin.

The prothrombin conversion time of the plasma determined by the two-stage method of Warner, Brinkhous and Smith (8) was found to be the same as that of normal plasma. This observation also confirms the view that the anticoagulant is not an antithrombin, since antithrombin is known to prolong the prothrombin conversion time.

\section{(3) Fractionation of the plasma}

\section{Separation of albumin and globulin}

Albumin and globulin were prepared from the plasma by precipitation with 21 per cent sodium sulfite (9). In one experiment the globulin was precipitated by direct addition of 19 volumes of 21 per cent sodium sulfite to the plasma. The precipitated globulin was centrifuged down, washed once with 21 per cent sodium sulfite and recentrifuged. It was then dissolved in $0.15 \mathrm{M}$ sodium chloride and dialyzed against $0.15 \mathrm{M}$ sodium chloride until free of sulfite.

Since this procedure diluted the albumin to such an extent that activity would not be demonstrable if present, a second precipitation was performed by dialysis of $10 \mathrm{ml}$. of the plasma against $190 \mathrm{ml}$. of 21 per cent sodium sulfite until equilibrium was reached. The contents of the dialysis bag were then centrifuged, the supernatant containing the albumin removed, the precipitate dissolved in $0.15 \mathrm{M}$ sodium chloride and both fractions were dialyzed against $0.15 \mathrm{M}$ sodium chloride until free of sulfite.

The results of this experiment (Table VII) in-

$1 \mathrm{We}$ are indebted to Dr. Irvine H. Page of the Lilly Research Laboratories, Indianapolis, Ind., for the protamine used.
TABLE VII

The activity of albumin and globulin fractions

$$
\text { Fraction }
$$

Whole plasma

min.

Globulin prepared by direct precipitation

Globulin prepared by dialysis

Albumin prepared by dialysis

44

43

60

* Each test was made using $0.2 \mathrm{ml}$. of the plasma or fraction, $0.4 \mathrm{ml}$. normal plasma and $0.6 \mathrm{ml}$. of $0.025 \mathrm{M}$ calcium chloride.

Coagulation time of normal plasma $4 \mathrm{~min}$.

dicate that the anticoagulant activity is precipitated with the globulin. Both globulin preparations had an activity equal to that of the plasma from which they were derived, while the albumin had no anticoagulant effect.

\section{Adsorption with aluminum hydroxide gel}

Aluminum hydroxide gel has been used extensively as an adsorbent of various proteins. In the field of blood coagulation it has been used in the preparation of prothrombin-free plasma (10). It appeared of interest to determine whether alumina gel would affect the activity of this anticoagulant.

The plasma was mixed with $1 / 10$ of its volume of alumina gel and incubated at $37^{\circ} \mathrm{C}$. with frequent stirring for 20 minutes, the alumina gel removed by centrifuging and the procedure repeated. This plasma had a prothrombin time by the onestage method of over 3 minutes. There was no change in the anticoagulant activity of the preparation compared to that of untreated plasma. So the anticoagulant is not adsorbed by alumina.

\section{Euglobulin preparation}

Considerable stress has been placed on the rôle of euglobulin preparations, of various types, in the field of blood coagulation. This fraction, prepared by dilution and isoelectric precipitation, is the starting material for the preparation of prothrombin (11). Euglobulin from normal plasma prepared either by dilution and isoelectric precipitation or by dialysis has been shown to contain a substance which accelerates the clotting of hemophilic blood, both in vivo and in vitro (12). A similar preparation has been shown to contain anticephalin (4). From this very incomplete discussion of the properties of euglobulin it is apparent 
TABLE VIII

Activity of euglobulin prepared by isoelectric precipitation

\begin{tabular}{lc}
\multicolumn{1}{c}{ Fraction } & $\begin{array}{c}\text { Coagulation time* } \\
\text { min. }\end{array}$ \\
Untreated plasma & 16 \\
Euglobulin & 1 \\
Alumina-treated plasma & 15 \\
Euglobulin & 3
\end{tabular}

* Each test was made using $0.2 \mathrm{ml}$. of the plasma or fraction, $0.4 \mathrm{ml}$. of normal plasma and $0.6 \mathrm{ml}$. $0.025 \mathrm{M}$ calcium chloride.

Coagulation time of normal plasma $6 \mathrm{~min}$.

that it must be a complex mixture of proteins having various activities in relation to the coagulation mechanism. That it is a complex mixture is borne out by the fact that electrophoretic analysis of chemically prepared euglobulin shows the presence of at least three components (13).

Since so many of the substances active in blood coagulation are euglobulins, it was of interest to determine whether this anticoagulant was contained in the euglobulin fraction of the plasma. Plasma prepared in the usual manner was divided and part of it treated with aluminum hydroxide gel to remove prothrombin. A part of each fraction was then diluted with 10 volumes of distilled

TABLE IX

Activity of euglobulin and supernatant

\begin{tabular}{c|c|c}
\hline \multirow{2}{*}{ Time of dialysis } & \multicolumn{2}{|c}{ Coagulation time* } \\
\cline { 2 - 3 } & Supernatant & Euglobulin \\
\hline days & $\min$. & $\min$. \\
2 & 18 & 7 \\
4 & 17 & 6 \\
7 & 10 & 6 \\
10 & 11 & 7 \\
\hline
\end{tabular}

* Each test was made using $0.2 \mathrm{ml}$. of the fraction, 0.4 ml. normal plasma and $0.6 \mathrm{ml}$. of $0.025 \mathrm{M}$ calcium chloride. Coagulation time of normal plasma 6 min.

water and brought to $\mathrm{pH} 5.5$ by the addition of 1 per cent acetic acid. The precipitates so formed were centrifuged down and dissolved in a volume of $0.15 \mathrm{M}$ sodium chloride equivalent to that of the plasma from which they were derived. The four fractions, namely the untreated plasma, the alumina treated plasma, and the euglobulins derived from them, were tested in the usual manner as shown in Table VIII.

The euglobulins prepared from both the untreated plasma and the alumina treated plasma were found to have no anticoagulant activity. Instead, they both displayed a marked clot accele- rating action toward normal plasma. This experiment suggested that the anticoagulant was not a euglobulin. Due to the dilution of the supernatant it was not possible to test it for anticoagulant activity. The possibility, therefore, existed that the anticoagulant was a euglobulin but had lost its activity during the procedures involved in the separation of the euglobulin. Euglobulin was accordingly separated by a method which did involve dilution of the supernatant. Plasma was freed of prothrombin by treatment with aluminum hydroxide gel and dialyzed in $5 \mathrm{ml}$. lots against repeated changes of distilled water. After the times shown in Table IX the precipitates were recovered by centrifuging and dissolved in a volume of $0.15 \mathrm{M}$ sodium chloride equivalent to that of the original plasma. Tests were made on the euglobulins and the supernatants. The supernatants had a definite anticoagulant activity, though not as great as that of the whole plasma. The euglobulins neither accelerated nor retarded the clotting of normal plasma.

\section{Ether extraction of liquid plasma}

Plasma obtained in the usual manner was shaken vigorously with one half its volume of ether for 60 seconds. The emulsion so formed was allowed to stand for two hours and then centrifuged. Three layers were formed consisting of ether, plasmaether emulsion and clear plasma. The plasma layer was removed, freed of ether by evacuation and adjusted to $\mathrm{pH}$ 7.4. This ether extracted plasma and the original plasma were compared in their anticoagulant activity against normal plasma. (Table X.)

There was no decrease in the anticoagulant activity of the plasma following ether extraction. From this experiment it is concluded that the active principle of this anticoagulant is not a free lipid, nor it is a loosely bound lipid protein complex such as the antithrombin described by Gruning (14). The possibility remains, however, that

TABLE $X$

$\begin{array}{cc}\text { The effect of ether extraction of the liquid plasma } \\ \text { Fraction } \\ \text { Coagulation time* } \\ \text { min. } \\ \text { Untreated plasma } & 60 \\ \text { Ether-extracted plasma } & 50\end{array}$

* Each test was made using $0.2 \mathrm{ml}$. of the plasma, 0.4 ml. of normal plasma and $0.6 \mathrm{ml}$. of $0.025 \mathrm{M}$ calcium chloride.

Coagulation time of normal plasma $6 \mathrm{~min}$. 
the anticoagulant is a lipoprotein which would not be affected by ether extraction.

\section{DISCUSSION}

The properties of the anticoagulants described by Lozner, Jolliffe and Taylor, by Lawrence and Johnson, and in this paper lead to the conclusion that the same substance is present in all three cases. A summary of these properties as found by the three groups of investigators is given in Table XI.

TABLE XI

Characteristics of circulating anticoagulant

\begin{tabular}{|c|c|c|c|}
\hline Characteristic & $\begin{array}{c}\text { Lawrence } \\
\text { and } \\
\text { Johnson }\end{array}$ & $\begin{array}{l}\text { Lozner, } \\
\text { Jolliffe and } \\
\text { Taylor }\end{array}$ & Munro \\
\hline $\begin{array}{l}\text { Prolongs coagulation time } \\
\text { of normal blood } \\
\text { Not destroyed by heating } \\
\text { Stable to pH } \\
\text { Shows antithrombin } \\
\text { activity } \\
\text { Neutralized by protamine } \\
\text { Passes through semi- } \\
\text { permeable membrane } \\
\text { Precipitated as euglobulin } \\
\text { Precipitated as globulin } \\
\text { Extracted by ether }\end{array}$ & $\begin{array}{c}\text { yes } \\
37.5^{\circ} \text { for } \\
30 \text { hours } \\
\text { not studied } \\
\text { no } \\
\text { no } \\
\text { no } \\
\text { not studied } \\
\text { not studied } \\
\text { no }\end{array}$ & $\begin{array}{l}\text { yes } \\
61^{\circ} \text { for } \\
10 \text { min. } \\
\text { not studied } \\
\text { no } \\
\text { no } \\
\text { no } \\
\text { no } \\
\text { not studied } \\
\text { no }\end{array}$ & $\begin{array}{c}\text { yes } \\
65^{\circ} \text { for } \\
10 \text { min. } \\
6.5 \text { to } 11.0 \\
\text { no } \\
\text { no } \\
\text { no } \\
\text { no } \\
\text { yes } \\
\text { no }\end{array}$ \\
\hline
\end{tabular}

It can be seen that in every case where the same characteristic was studied there is agreement as to the behavior of the anticoagulant.

None of the investigators of this anticoagulant have been able to classify it in any of the groups of potential anticoagulants described by Quick. These groups include antagonists to each of the five factors which participate in the coagulation mechanism. It is apparent therefore that this anticoagulant must fall into one of these groups and failure to identify its type is the result of the inadequacy of the methods available for studying such anticoagulants. With the development of more precise methods it should be possible to determine which phase of the coagulation mechanism is inhibited by this anticoagulant.

The chemical behavior of the substance indicates that the activity is associated with a protein molecule, probably a globulin. This is supported by the fact that the activity is not impaired by dialysis and that on precipitation of the plasma with sodium sulfite the anticoagulant activity is found in the globulin fraction.

\section{SUM MARY}

The properties of a circulating anticoagulant found in the blood of a hemophiliac have been in- vestigated. The relation of the anticoagulant to the coagulation mechanism has been studied but its nature has not been determined. Chemically, the anticoagulant activity appears to be associated with the globulin fraction of the plasma.

This work was carried out with the technical assistance of Miss Annabel Avery, B.A. Acknowledgment is made of the cooperation of Miss Lucille J. Heckman, M.T., in collecting the blood samples used in this study.

\section{BIBLIOGRAPHY}

1. Munro, F. L., and Jones, H. W., The detrimental effect of frequent transfusions in the treatment of a patient with hemophilia. Am. J. M. Sc., 1943, 206, 710.

2. Lawrence, J. S., and Johnson, J. B., The presence of a circulating anticoagulant in a male member of a hemophiliac family. Tr. Am. Clin. and Climatol. A., 1942, 57, 223.

3. Lozner, E. L., Jolliffe, L. S., and Taylor, F. H. L., Hemorrhagic diathesis with prolonged coagulation time associated with a circulating anticoagulant. Am. J. M. Sc., 1940, 199, 318.

4. Tocantins, L. M., Demonstration of antithromboplastic activity in normal and hemophilic plasmas. Am. J. Physiol., 1943, 139, 265.

5. Howell, W. H., The condition of the blood in hemophilia, thrombosis, and purpura. Arch. Int. Med., 1914, 13, 76.

6. Quick, A. J., The Hemorrhagic Diseases and the Physiology of Hemostasis. Charles C. Thomas, Springfield, 1942.

7. Wilson, S. J., Quantitative studies on antithrombin. Arch. Int. Med., 1942, 69, 647.

8. Warner, E. D., Brinkhous, K. M., and Smith, H. P., A quantitative study on blood clotting: prothrombin fluctuations under experimental conditions. Am. J. Physiol., 1936, 114, 667.

9. Campbell, W. R., and Hanna, M. I., The albumin, globulins, and fibrinogen of serum and plasma. J. Biol. Chem., 1937, 119, 15.

10. Quick, A. J., On the relationship between complement and prothrombin. J. Immunol., 1935, 29, 87.

11. Seegers, W. H., Purification of prothrombin and thrombin: chemical properties of purified preparations. J. Biol. Chem., 1940, 136, 103.

12. Patek, A. J., Jr., and Taylor, F. H. L., Hemophilia; some properties of a substance obtained from normal human plasma effective in accelerating the coagulation of hemophilic blood. J. Clin. Invest., 1937, 16, 113.

13. Tiselius, A., Electrophoresis of serum globulin; electrophoretic analysis of normal and immune sera. Biochem. J., 1937, 31, 1464.

14. Grüning, W., Zur Frage der chemischen Natur des Antithrombins. Pflügers Arch. f. d. ges. Physiol., 1943, 247, 292. 